\title{
RIBEIRO, Gustavo Lins \& ESCOBAR, Artur (orgs.). Antropologias Mundiais: transformações da disciplina em sistemas de poder
}

\section{Stephen G. Baines}

\section{(2) OpenEdition Journals}

Edição electrónica

URL: http://journals.openedition.org/aa/722

DOI: $10.4000 /$ aa. 722

ISSN: 2357-738X

Editora

Programa de Pós-Graduação em Antropologia Social (UnB)

\section{Edição impressa}

Data de publição: 1 junho 2014

Paginação: 259-262

ISSN: 0102-4302

\section{Refêrencia eletrónica}

Stephen G. Baines, «RIBEIRO, Gustavo Lins \& ESCOBAR, Artur (orgs.). Antropologias Mundiais: transformações da disciplina em sistemas de poder», Anuário Antropológico [Online], v.39 n. 1 | 2014, posto online no dia 01 outubro 2014, consultado o 27 abril 2021. URL: http://journals.openedition.org/ aa/722 ; DOI: https://doi.org/10.4000/aa.722

Este documento foi criado de forma automática no dia 27 abril 2021.

\section{c) (†) $९$}

Anuário Antropológico is licensed under a Creative Commons Atribuição-Uso Não-Comercial-Proibição de realização de Obras Derivadas 4.0 International. 


\title{
RIBEIRO, Gustavo Lins \& ESCOBAR, Artur (orgs.). Antropologias Mundiais: transformações da disciplina em sistemas de poder
}

\author{
Stephen G. Baines
}

\section{REFERÊNCIA}

RIBEIRO, Gustavo Lins \& ESCOBAR, Artur (orgs.). Antropologias Mundiais:

transformações da disciplina em sistemas de poder. Brasília: Editora UnB. 472 pp

1 O objetivo desta coletânea é explorar a diversidade de antropologias praticadas em diversos países do mundo no início do século XXI, visando contribuir para a criação de uma comunidade transnacional de antropologia dentro de um projeto chamado "Antropologias Mundiais". o volume parte da premissa de que a globalização permitiu que "os objetos de estudo" da antropologia, os povos nativos do planeta, passassem à posição de sujeitos. O livro e projeto que o inspirou objetivam transcender dicotomias como ocidental e não ocidental, centro e periferia, hegemônico e não hegemônico etc., para considerar os espaços comuns onde as antropologias têm se encontrado e podem se encontrar no futuro. As críticas levantadas pelos organizadores do livro das trocas desiguais entre as antropologias visam ir além das estruturas de poder, vendo a assimetria nos termos da tensão entre o que chamam de "provincianismo metropolitano" e "cosmopolitanismo provinciano" (:32).

2 A coletânea reúne contribuições de 13 autores, além dos dois organizadores, com objetivo otimista de ampliar os horizontes antropológicos tendo em vista o enriquecimento da antropologia como uma cosmopolítica mais rica que valoriza a pluralidade e a diversidade. Apesar de ser obviamente impossível em uma resenha captar a riqueza dos argumentos e das sutilezas de reflexões sobre uma temática em si 
muito complexa no conteúdo dos 14 artigos que compõem este volume, comento brevemente alguns dos temas. O livro é dividido em quatro seções. A seção I é composta de cinco artigos sob o título "Transnacionalismo e poder estatal", e tem uma contribuição dos organizadores, Gustavo Lins Ribeiro e Arturo Escobar, que abordam as transformações disciplinares em sistemas de poder que acompanham o processo de globalização e visam ao estabelecimento de relações mais horizontais entre as diferentes antropologias praticadas em países diversos. 0 segundo artigo, de autoria de Shinji Yamashita, versa sobre a questão das antropologias mundiais a partir de uma visão do Japão. Após esboçar a história da disciplina no Japão, Yamashita afirma que “antropólogos japoneses agem como se pertencessem a um país colonizado (em relação aos Estados Unidos), raramente pesquisando a metrópole [...] mas importando teorias americanas e europeias para usar no seu trabalho" (:64).

O trabalho seguinte, de autoria de Nikolai Vakhtin, examina as transformações da antropologia siberiana vista de dentro da Rússia. A transição da era soviética, em que os etnógrafos russos tinham de trabalhar sob intensa pressão ideológica segundo o paradigma teórico sancionado pelo Estado, de reduzir o nacional ao étnico, com a queda da União Soviética em 1991, resultou na internacionalização da pesquisa siberiana com um influxo de muitos antropólogos do Ocidente, sobretudo estadunidenses, o que criou uma tensão entre estes e os russos. O quarto artigo, de autoria de Josephine Smart, professora radicada no Canadá, aborda a antropologia na China como "disciplina presa em uma tela de construção da nação" (:105) ao examinar a disciplina no contexto do capitalismo socialista que surgiu da reforma econômica pós-1978. Como nos outros artigos, a autora esboça a história da antropologia na China, ressaltando a dificuldade de praticar uma antropologia crítica livre da ideologia de intervenção do Estado. A autora apresenta também a antropologia em Taiwan e Hong Kong. $\mathrm{O}$ artigo seguinte, escrito por Esteban Krotz, antropólogo espanhol radicado há muitos anos no México, trata da antropologia no México, uma prática profissional, conforme este autor, que está enraizada na busca identitária da nação mexicana. Após caracterizar o México como país, Krotz argumenta que a disciplina esteve "tão ligada ao sistema político e sociocultural do país que seria impossível entendê-la sem referência a ele" (:152).

4 A seção II do livro, sobre poder e hegemonia da antropologia, é composta de três artigos. O primeiro, de autoria do finado Eduardo P. Archetti, antropólogo de origem argentina radicado na Noruega, discute a problemática de centros e periferias na antropologia a partir da França, um dos três centros tradicionais de formação e consolidação da disciplina junto com os Estados Unidos e a Grã-Bretanha. Archetti conclui que "a antropologia francesa tem sido uma arena central na constituição da antropologia internacional e uma fonte para a disciplina como um todo" (:187), sobretudo na teoria e pensamento filosófico, "[...] agora é a hora de desenvolver uma análise crítica sistemática dessa 'tradição', examinando algumas das ambiguidades e contradições [...]" (:187). Comenta o autor que a influência de Louis Dumont é menos importante na França do que em "periferias" da antropologia, "tais como o Brasil e a Noruega" (:187).

5 O segundo artigo, escrito por Susana Narotzky, aborda a teoria antropológica no contexto das lutas políticas na Espanha, explorando três discursos: da singularidade e da consciência autônoma; da participação em um projeto político local; e do realismo etnográfico, como tentativas de ir além da desqualificação de formas particulares não hegemônicas. A autora examina o que identifica como uma dupla colonização no caso 
da Andaluzia - de antropólogos estrangeiros e teórica - ressaltando que "é inevitável o posicionamento político na produção do conhecimento antropológico" (:217) e que "apenas formas hegemônicas de conhecimento apresentam a si mesmas como apolíticas" (:220). O terceiro artigo, de autoria de Paul Nchoji Nkwi, professor de antropologia em Camarões, trata da antropologia na África pós-colonial, focalizando alguns paradoxos da antropologia em determinados países daquele continente, decorrentes da rejeição da antropologia como um culto ao primitivismo e apologia ao colonialismo. A antropologia, praticada frequentemente em difíceis condições, tinha de se redescobrir como disciplina acadêmica e como prática engajada que pudesse ajudar a resolver problemas (NKWI, 2012).

6 A seção III do livro é constituída de quatro artigos organizados em torno de dilemas disciplinares, sociológicos e epistemológicos. O primeiro, de autoria de Eeva Berglund, antropóloga de origem escandinava, radicada em Londres, onde é pesquisadora independente, discute a antropologia no Reino Unido, país tradicionalmente central na formação histórica e na consolidação da disciplina. Em Londres, seguindo uma tendência das últimas décadas nos "países de centro" da antropologia, há um crescente interesse de acadêmicos em pesquisas sobre modernidade nos seus próprios países (: 256), em contextos de transformações nas universidades, como "os intensos esforços do capital privado em penetrar - ou engolir - a produção do conhecimento acadêmico" (: 255).

7 O segundo artigo desta seção, escrito por Marisol de la Cadena, antropóloga nascida em Lima, Peru, e radicada nos Estados Unidos, focaliza a antropologia andina, sobretudo no Peru, traçando a sua história nesse país em um contexto em que se constituíram "formações acadêmicas (e intelectuais) regionais com seus próprios centros" (:284), que "compreendem uma complexa configuração de múltiplos centros hierarquicamente organizados, alguns dos quais são 'periféricos' em relação a outros 'mais centrais"' (: 284). Esta autora afirma que "a antropologia está em uma posição de contribuir para a visibilidade de outras formas de conhecimento" (:314), sendo necessária "uma consciência do pensamento antropológico como um processo dialógico de tradução entre o local e o universal, entre histórias e História, entre o singular e o geral (:314).

O terceiro artigo, escrito por Sandy Toussaint, antropóloga australiana, aborda as "antropologias australianas em processo de transformação" (:315), e nele a autora apresenta um exemplo do uso do conhecimento antropológico além do "centro" de sua própria produção: "uma demanda australiana por um título de território nativo ajuda a iluminar uma análise que repousa sobre a hibridez das antropologias australianas no seu processo de transformação" (:315-316). Toussaint mostra como a antropologia se transformou em resposta ao contexto local deste país e a enorme demanda por parte dos indígenas e do Estado para o trabalho do antropólogo na regularização de territórios indígenas, sendo "um forte campo de engajamento que tem gerado significativo interesse intelectual e emprego para os antropólogos australianos nos anos recentes" (:330).

O quarto artigo, de autoria de Shiv Visvanathan, apresenta a "hegemonia oficial e pluralismos contestatórios" no caso da antropologia na Índia a partir de uma análise da complexa história da disciplina naquele país. $O$ autor afirma que a antropologia na Índia, após décadas de diálogos e debates com acadêmicos no Ocidente, alcançou uma maturidade própria para "ir além do ressentimento do orientalismo e pluralizar a perspectiva colonizadora" (:335). A disciplina no contexto indiano vem acompanhando 
as peripécias da história pós-colonial e se abre como projeto para abranger perspectivas diversificadas e múltiplas que dialogam tanto com o nacional quanto com o universal.

10 Na seção IV da coletânea, "Da antropologia atual às antropologias mundiais", há dois artigos, o primeiro escrito por Otávio Velho sobre o Brasil. Assevera Velho que "A 'antropologia brasileira' (ou a 'antropologia no Brasil', se preferirmos enfatizar o universalismo) tem obtido considerável prestígio social (e tamanho) desde a década de 1960" (:372), com grande influência pública. Este autor chama a atenção para os problemas complexos na comunicação internacional entre os antropólogos, permeada por assimetrias de poder. $\mathrm{O}$ último artigo da coletânea, escrito por Johannes Fabian, levanta questões sobre antropologias mundiais e afirma que o livro "'Antropologias mundiais' descreve um estado que já existe em alguns níveis do discurso e da prática" (: 411), no sentido de que, nos crescentes intercâmbios internacionais da disciplina que rompem com as antigas hierarquias e hegemonias, já existe o surgimento de uma antropologia planetária.

11 Os artigos que constituem este importante livro, leitura obrigatória para quem se interessa pelas transformações da antropologia e as possibilidades de diálogos transnacionais entre antropólogos, levantam muitas perguntas e temas que revelam a complexidade da proposta, ainda algo utópica - perguntas que muitas vezes não têm respostas, mas que apontam caminhos, num mundo globalizado, para o desafio de estabelecer trocas mais horizontais entre os antropólogos em diversos países do mundo.

\section{AUTORES}

\section{STEPHEN G. BAINES}

UnB 